\title{
Can Social Mobility Alleviate Anxiety? An Empirical Analysis Based on the CGSS
}

\author{
Junhui $\operatorname{Han}^{1}$ \\ ${ }^{1}$ School of Economics and Management, Taiyuan University of Technology \\ Correspondence: Junhui Han, School of Economics and Management, Taiyuan University of Technology, No. 209, \\ University Street, Yuci District, 030600 Jinzhong, China.
}

Received: June 28, 2021

doi:10.11114/ijsss.v9i5.5295
Accepted: July 8, $2021 \quad$ Available online: July 16, 2021

URL: https://doi.org/10.11114/ijsss.v9i5.5295

\begin{abstract}
With the aggravation of social competition, more and more people fall into anxiety, depression and even suicide. How to alleviate individual anxiety and then avoid the spread of social anxiety? Academic circles have been very concerned about the impact of social mobility on individual political attitude, psychology and behavior. Can social mobility alleviate individual anxiety? What is the underlying mechanism? Based on 17192 samples in 2010, 2012, 2013 and 2015 from Chinese General Social Survey (CGSS), the paper attempts to study the impact of social mobility on individual anxiety and the mediating effect of Self assessment on family economic status. The ordered probit regression model showed that the increase of positive mobility distance can alleviate individual anxiety to a certain extent, whether it is intra or inter-generational social mobility. Meamwhile, the higher the score of subjective class identification, the lower the degree of anxiety. The results also showed that self assessment on family economic status has a significant mediating effect on the relationship among social mobility and individual anxiety.
\end{abstract}

Keywords: social mobility, subjective class identification, anxiety, mediating effect

\section{Introduction}

From the individual level, anxiety is a kind of self-protection emotional reaction when facing future uncertainty and lack of coping methods (Tashiro Nobuo, 2008). In other words, it is a kind of uncomfortable worry. Its object is vague and unrecognized threats and difficulties which make people feel that they will exist at some time in the future(Lauren B.Alloy et al, 2005). According to the Report on the China's Migrant Population Development in 2011, 47\% of the new generation of migrant workers are "full" of anxiety due to low income, uncertain future, neglect of taking care of their children and other reasons (Department of Migrant Population Services Management in China,2011). At the same time, anxiety, depression, suicide and other "official mental illness" are also common in newspapers or the Internet. And the middle-class families in the "sandwich layer" are enveloped by "inexplicable" anxiety. According to the Report on the Living Conditions of White-Collar Workers in 2018 released by Zhaopin, nearly 95\% of white-collar workers in the workplace are anxious (Zhaopin,2018). Mainstream media even states that China has entered a period of "national anxiety", and anxiety is becoming a common phenomenon in society (Shi and Zhao, 2011).

How to understand and interpret the above phenomenon? Besides personal characteristics, are there social factors? Existing studies show that social structural factors such as subjective (objective) social status in a static sense are closely related to anxiety (Hua and Weng, 2013). However, from dynamic view, what is the impact of intra and inter-generational social mobility on individual anxiety? Few studies have discussed this issue. Obviously, the discussion of this issue can not only deepen the sociological causes of anxiety, but also provide reference for promoting the formulation of social mobility policy.

For above considerations, subjective class identification is regarded as static indicator, social mobility perception and intergenerational social mobility as dynamic indicator. Firstly, this paper studies the influence of social mobility on individual anxiety from static and dynamic perspectives. Secondly, this paper tests the mediating effect of self assessment on family economic status. Finally, the conclusion and discussion are given. 


\section{Literature Review}

\subsection{Social Mobility and the Changing Trend of Class Structure}

Since the 1990s, sociologists have begun to pay attention to the new changes in China's social class structure, and basically had three different judgments, namely, the "stratification theory" , "fragmentation theory" and "fracture theory" (Lu,2004; Li ,2011; Sun ,2003). The studies not only express the optimistic sentiment that "Chinese class structure is being stratified", but also have the pessimistic argument that "the upper and lower classes are isolated from each other". In the new century, the trend of vertical social mobility has weakened (Zhang, 2011). Further research shows that social mobility in China exists class segmentation and internal closure ( $\mathrm{Li}, 2006)$. It can be said that the academic circles is more inclined to the view that the current social class structure is stereotyped in china $(\mathrm{Li}, 2011)$.

\subsection{Research Contexts of Social Anxiety}

How does anxiety and social anxiety gradually step into the scope of social mobility research? At first, anxiety research is mostly based on the level of personality characteristics (Tashiro Nobuo, 2008). After all, the real world is made up of countless individuals. Some scholars try to explain social phenomena with anxiety. For example, views like the individual's "common" anxiety leads to "clearly identified actions", "capitalist anxiety" and others are seen in many studies(Hunt,1999; Gay,1984). In addition, what is the difference between social anxiety and individual anxiety? The answer is to extend individual attributes to the whole society. Of course, social anxiety is not a simple accumulation of individual anxiety, but a general state of tension among social members (Wu, 1993). Maybe social anxiety is different from social activities anxiety, and social tension plays an important role in the formation and development of social anxiety (Qiu, 2003). In fact, when anxiety transcends individual emotions and becomes a social public distress, it is necessary to make a social structural explanation (Sun, 2016).

\subsection{Relationship between Anxiety and Social Structure}

\subsubsection{Relationship between Class Status and Anxiety from a Static Perspective}

The above studies have deepened the sociological understanding of anxiety, but is there any relationship between anxiety and social structure? Under the influence of class structure, if the number of anxious people is increasing, it means that there are problems in the class structure of this society (Hua and Weng ,2013). Furthermore, many psychological studies also believe that individual status and social "status" are interrelated, and social anxiety may be a reflection of social class structure. From an objective perspective, different classes have different survival anxiety and development panic (Wei, 2017). Due to the large number of individuals in the middle and lower classes, the relative scarcity of resources and the relative squeeze of survival and development make them more prone to anxiety; and the anxiety of the upper dominated groups is less. In addition, the social public's class subjective identification shows an obvious "downward" tendency, as the middle class's subjective identification accounts for less and the lower class's subjective identification accounts for more $(\mathrm{Gu}, 2015)$. Does the lower class identification represent anxiety and helplessness? Research shows that the lower the comprehensive evaluation of one's economic and social status, the more likely it is to be anxious (Kohn, et al., 1997) (Hua and Weng, 2013). It can be said that both objective class status and subjective class identification (evaluation) have a negative relationship with individual anxiety.

\subsubsection{Relationship between Class Status and Anxiety from a Dynamic Perspective}

The above studies mainly study the influence of social status on individual anxiety from a static perspective. From a dynamic perspective, what is the impact of social mobility (or social status change) on individual anxiety? The literature mainly discusses the impact of class mobility on individual psychological and behavioral choice. For example, the "stratification theory" holds that when social individuals leave the original social class, it will bring psychological pressure, which makes individuals pay more attention to personal interests and ignore the interests of others, showing a lower willingness to participate in society (Daenekindt, 2017). Studies on happiness find that upward mobility can positively predict the individual happiness, while downward mobility has a significant negative impact on happiness (Chan, 2017). The theory of social causality and health choice mainly discuss the relationship between social mobility and individual health. The former states that social economic status determines health, while the latter believes that health is the social mechanism for individuals to realize upward mobility.

In short, what is the impact of social mobility on anxiety? Few studies have discussed this issue. Considering that the subjective evaluation of class mobility often has a greater impact on the individual's attitude or behavior willingness than the objective class mobility (Merkl and Turner ,1993). Based on the above studies, this paper attempts to explore the influence of intra or inter-generational social mobility on anxiety from the perspective of subjective evaluation. 


\section{Data and Model Description}

\subsection{Data Sources}

This paper mainly uses data from Chinese General Social Survey (CGSS). This database is jointly developed by the Department of Sociology of Renmin University of China and the research center of Hong Kong University of Science and Technology. The database mainly aims at the major practical and theoretical problems in the process of social transformation in China, and comprehensively reflects the basic information of residents' thinking, behavior patterns and social changes from multiple dimensions. Currently, the data of CGSS has become an important reference for academic research and policy-making. The data can be downloaded from CNSDA. Considering the timeliness and availability of data, this paper uses the data of CGSS in 2010, 2012, 2013 and 2015. According to the purpose of this study, after deleting the missing values, the authors finally retained 4524 samples in 2010, 4583 samples in 2012, 4541 samples in 2013 and 3544 samples in 2015, a total of 17192 samples.

\subsection{Variable Selection}

\subsubsection{Dependent Variable}

In the Chinese General Social Survey (CGSS) questionnaire, the question related to anxiety is "how often did you feel depressed or upset in the past four weeks?". According to the respondents' answers to this question, we assign "always" to 5 , "often" to 4 , "sometimes" to 3 , "rarely" to 2 , "never" to 1.

\subsubsection{Independent Variable}

Including the subjective class identification in the static sense and the subjective social mobility variable in the dynamic sense. Subjective class identification is the positioning of an individual's social status after the overall evaluation of economic ability and social capital (Kraus et al, 2012). In the Chinese General Social Survey (CGSS) questionnaire, the interviewees were shown a picture of a ten-step ladder, marked with 1-10 from lower to top. The highest "10" represents the top class, and the lowest "1" represents the lower class. The interviewees were required to choose a number to express their subjective class according to their comprehensive judgment. The larger the number is, the higher the evaluation of their class is.

The subjective social mobility variables in the dynamic sense include the perceptions of intra and inter-generational social mobility. These variables reflect the subjective evaluation of individual or family on the change of social status in a certain period. The Chinese General Social Survey (CGSS) questionnaire not only contains "what level do you think you are in now?", but also reports "what level do you think you were 10 years ago?". In this paper, the perception of intragenerational social mobility (or Social mobility perception) is defined as the present subjective class score minus the subjective class score 10 years ago. Similarly, the present subjective class score minus the family class score at their age of 14 is taken as the intergenerational social mobility.

\subsubsection{Control Variable}

Including individual and family control variables. At the individual level, the control variables include marital cohabitation, individual health, gender, age, education and occupational status. The family control variable is registered residence. Considering the individual anxiety often needs emotional and financial support from their families, especially their spouses, we investigate the variable of marital cohabitation according to whether they live together or not, which is different from most previous studies. The four conditions of "unmarried", "separated without divorce", "divorced" and "widowed" in the questionnaire are regarded as "divorced" and assigned to 0 , while the other situations are assigned to 1 , which means "married". The self-assessment of physical health in the questionnaire was used for individual health status. In addition, the occupational status of the interviewees were involved in the questionnaire. For example, "in the current position, does anyone often want you to help him/her through your work?" This variable of occupational status is measured by the answer to this item.

\subsubsection{Mediating Variable}

Generally speaking, the higher the family income is, the lower the individual anxiety level may be. Family income can be regarded as a measure of objective class status to a certain extent. But this paper pays more attention to the individual's subjective judgment of family income. After all, the subjective judgment of family economic status is more likely to be closely related to individual anxiety. Therefore, we used the answer to the question of "What level of your family economy is in the local area" to measure the self assessment on family economic status. 
Table 1. Variable and Descriptive Statistics

\begin{tabular}{|c|c|c|c|c|c|}
\hline Variable & Mean & S D & Min & Max & Variable description \\
\hline Individual anxiety & 1.9644 & 0.9178 & 1 & 5 & $\begin{array}{l}\text { Always }=5 \text {, often }=4 \text {, sometimes }=3 \text {, } \\
\text { rarely }=2 \text {, never }=1\end{array}$ \\
\hline Subjective class identification & 4.4234 & 1.6394 & 1 & 10 & $\begin{array}{l}\text { Estimated score of subjective current } \\
\text { class }\end{array}$ \\
\hline Social mobility perception & 0.7793 & 1.5695 & -9 & 9 & $\begin{array}{l}\text { Present subjective class score minus the } \\
\text { subjective class score } 10 \text { years ago }\end{array}$ \\
\hline Intergenerational social mobility & 0.9987 & 1.9040 & -9 & 9 & $\begin{array}{l}\text { Present subjective class score minus the } \\
\text { family class score at their age of } 14\end{array}$ \\
\hline Self assessment on family economic status & 2.7573 & 0.6924 & 1 & 5 & Local level of family economic status \\
\hline Age & 40.6657 & 18.8181 & 18 & 60 & Survey year minus birth year \\
\hline Education & 10.9745 & 3.4659 & 1 & 15 & $\begin{array}{l}\text { No formal education }=1 \text {, primary } \\
\text { school }=6 \text {, junior high school }=9 \text {, senior } \\
\text { high school }=12 \text {, junior college or } \\
\text { above }=15\end{array}$ \\
\hline Marital cohabitation & 0.8234 & 0.3810 & 0 & 1 & $\begin{array}{l}\text { Unmarried, separated without divorce, } \\
\text { divorced and widowed }=0 \text {, other } \\
\text { cohabitation }=1\end{array}$ \\
\hline Occupational status & 1.9718 & 1.0255 & 1 & 5 & $\begin{array}{l}\text { Always }=5 \text {, often }=4 \text {, sometimes }=3 \text {, } \\
\text { rarely }=2 \text {, never }=1\end{array}$ \\
\hline Gender & 0.5931 & 0.4913 & 0 & 1 & Male $=1$, female $=0$ \\
\hline Health status & 4.0045 & 0.9105 & 1 & 5 & $\begin{array}{l}\text { Very unhealthy }=1 \text {, relatively unhealthy }=2 \text {, } \\
\text { common }=3 \text {, relatively healthy }=4 \text {; very } \\
\text { healthy }=5\end{array}$ \\
\hline Registered residence & 0.4018 & 0.4903 & 0 & 1 & Rural $=1$, city $=0$ \\
\hline
\end{tabular}

\section{Empirical Results and Discussion}

\subsection{Ordered Probit Model Regression Results of the Influencing Factors of Individual Anxiety}

In this paper, individual anxiety is divided into five ordered levels: 1,2,3,4,5; while controlling the demographic variables such as marital cohabitation, age and so on, the ordered probit model is used to analyze the influence of subjective class identification, intergenerational social mobility and social mobility perception on individual anxiety, which are model 1, model 2 and model 3 respectively. From table2, the control variables including marital cohabitation, age, health, gender and registered permanent residence have different effects on individual anxiety. In model 1-3, the coefficients of marital cohabitation fluctuate is about -0.12 , and they are highly significant at the level of 0.01 , which means that living together can alleviate the anxiety. In fact, spouse or couple living together can provide emotional and financial support for each other, which will reduce anxiety to a certain extent. Anxiety can be a psychological problem, but also closely related to physical health. The coefficient in model 1-3 showed that there is a negative relationship between health status and individual anxiety, which are significant at the level of 0.01 . This shows that poor health status may lead to anxiety. Anxiety also shows significant gender differences. The regression coefficient gender in models are all negative and significant at the level of 0.01. Compared with men, women are more anxious. In addition, the influence of age on individual anxiety is significant at the level of 0.01. It can be seen that with the growth of age, the degree of anxiety has a slight decline. It means that young people are more anxious than the elderly. In fact, young people may be more anxious because of the pressure of employment, children's education and parents' pension. The results show that the coefficient of education is negative in three models, which is significant at the level of 0.01; and the regression coefficient of education square is positive. There is a U-shaped relationship between education and anxiety, but it is not significant. In addition, this paper defines occupational status as "the frequency that others want to ask for your help". The results showed that the higher the occupational status, or the higher the frequency of helping others due to work position, the higher the degree of individual anxiety. Maybe it means that the more complex the interpersonal relationship dealing with at work, the more anxious it is. Finally, the results show that the population in rural areas is more anxious.

After controlling the control variables such as marital cohabitation and age, we can see from model 1 that the regression coefficient of subjective class identification is -0.0676 , and it is highly significant at the level of 0.01 . This shows that the higher the score of subjective class identification, the lower the degree of anxiety. The regression results of model 2 show that the regression coefficient of intergenerational mobility is -0.0224 , and it is highly significant at the level of 0.01. It means that if the individual's current class score is greater than the family class status at their 14 years old, their anxiety will reduce to a certain extent. The results of model 3 show that there is a significant negative relationship between social mobility distance and individual anxiety. The coefficient is -0.0242 , which is significant at the level of 
0.01 , that is, if the intragenerational social mobility distance is doubled, the individual's anxiety level will be significantly reduced by about 0.0242 probit units. Overall, from model 1 to model 3 , whether upward mobility is intra or intergenerational, it can alleviate individual anxiety.

Table 2. Ordered Probit Regression Model of Individual Anxiety

\begin{tabular}{|c|c|c|c|}
\hline & Model 1 & Model 2 & Model 3 \\
\hline Marital cohabitation & $\begin{array}{l}-0.115^{* * * *} \\
(0.0239)\end{array}$ & $\begin{array}{l}-0.126^{* * * *} \\
(0.0239)\end{array}$ & $\begin{array}{l}-0.129^{* * * *} \\
(0.0239)\end{array}$ \\
\hline Health status & $\begin{array}{l}-0.397^{* * * *} \\
(0.00973)\end{array}$ & $\begin{array}{l}-0.408^{* * * *} \\
(0.00969)\end{array}$ & $\begin{array}{l}-0.409^{* * * *} \\
(0.00968)\end{array}$ \\
\hline Gender & $\begin{array}{l}-0.139^{* * * *} \\
(0.0172)\end{array}$ & $\begin{array}{l}-0.124^{* * * *} \\
(0.0172)\end{array}$ & $\begin{array}{l}-0.126^{* * * *} \\
(0.0172)\end{array}$ \\
\hline Age & $\begin{array}{l}-0.0920^{* * * *} \\
(0.0342)\end{array}$ & $\begin{array}{l}-0.0899^{* * * *} \\
(0.0343)\end{array}$ & $\begin{array}{l}-0.119^{* * * * *} \\
(0.0344)\end{array}$ \\
\hline Registered residence & $\begin{array}{l}0.0659^{* * *} \\
(0.0199)\end{array}$ & $\begin{array}{l}0.0728^{* * * *} \\
(0.0200)\end{array}$ & $\begin{array}{l}0.0713^{* * * *} \\
(0.0200)\end{array}$ \\
\hline Education square & $\begin{array}{l}0.000932^{*} \\
(0.000541)\end{array}$ & $\begin{array}{l}0.000664 \\
(0.000541)\end{array}$ & $\begin{array}{l}0.000611 \\
(0.000540)\end{array}$ \\
\hline Education & $\begin{array}{l}-0.0335^{* * * *} \\
(0.0109)\end{array}$ & $\begin{array}{l}-0.0337^{* * * *} \\
(0.0109)\end{array}$ & $\begin{array}{l}-0.0325^{* * * *} \\
(0.0109)\end{array}$ \\
\hline occupational status & $\begin{array}{l}0.0720^{* * * * *} \\
(0.00838)\end{array}$ & $\begin{array}{l}0.0626^{* * * *} \\
(0.00834)\end{array}$ & $\begin{array}{l}0.0626^{* 3 * 3} \\
(0.00834)\end{array}$ \\
\hline $\begin{array}{l}\text { Subjective class } \\
\text { identification }\end{array}$ & $\begin{array}{l}-0.0676^{* * * *} \\
(0.00528)\end{array}$ & & \\
\hline $\begin{array}{l}\text { Intergenerational } \\
\text { social mobility }\end{array}$ & & $\begin{array}{l}-0.0224^{* * * *} \\
(0.00447)\end{array}$ & \\
\hline $\begin{array}{l}\text { Social mobility } \\
\text { perception }\end{array}$ & & & $\begin{array}{l}-0.0242^{* * * *} \\
(0.00538)\end{array}$ \\
\hline Pseudo - $\mathrm{R}^{2}$ & 0.0536 & 0.0504 & 0.0503 \\
\hline Observations & 17192 & 17192 & 17192 \\
\hline
\end{tabular}

Note: (1) standard errors are shown in brackets; $(2) * * * *$, and $*$ are significant at $1 \%, 5 \%$ and $10 \%$ levels, respectively. Due to the limitation of space, the estimation of each tangent point is omitted here.

\subsection{Mediating Effect Analysis}

As mentioned above, the upward mobility can alleviate individual anxiety to a certain extent. What is the underlying mechanism? This paper attempts to analyze the mediating effect of self assessment about family economic status on the relationship between social mobility and individual anxiety. From the results in table2, we can see that intra or inter-generational social mobility and subjective class identification have a significant impact on individual anxiety, which can be analyzed according to the mediating effect model. Figure 1-3 further shows the mediating effects of self assessment on family economic status.

we analyze the Path coefficient in Figure 1 . The influence of subjective class identification on family economic status is 0.1798 , which is significant at the level of 0.01 ; furthermore, when subjective class identification and family economic status enter the equation at the same time, the regression coefficients of the two are -0.0672 and -0.1484 , which are highly significant at the level of 0.01 . This not only means that the direct effect of subjective class identification on individual anxiety is significant, but also the indirect effect of family economic status on the relationship between subjective class identification and individual anxiety is significant with partial mediating effect. Figure 2 and Figure 3 can be analyzed similarly. We can see that the self assessment on family economic status play significant mediating role between intergenerational social mobility, social mobility perception and individual anxiety. 


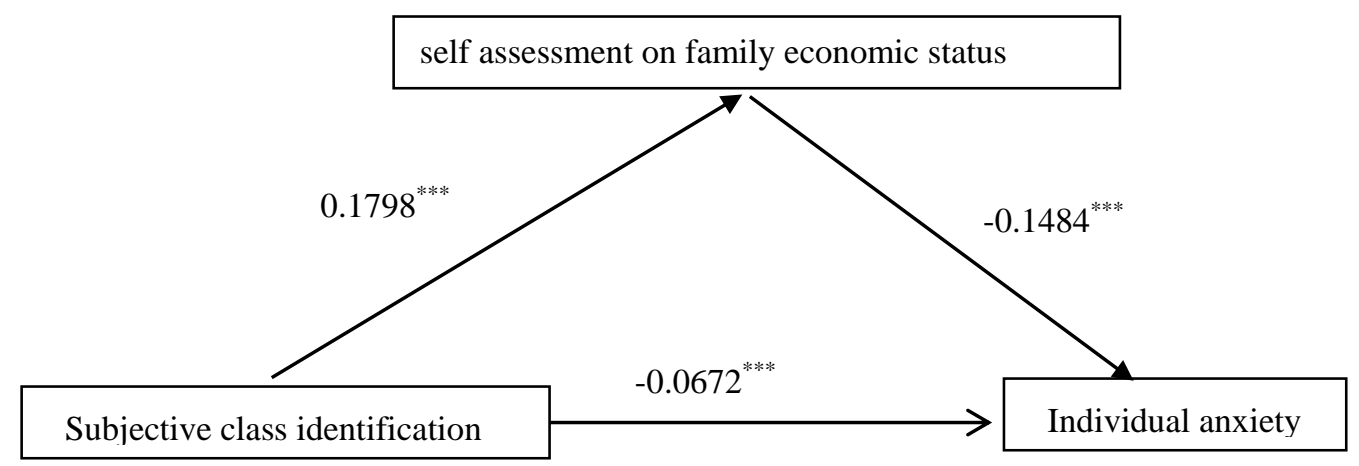

Figure 1 . The mediating effects of family economic status between subjective class identification and anxiety

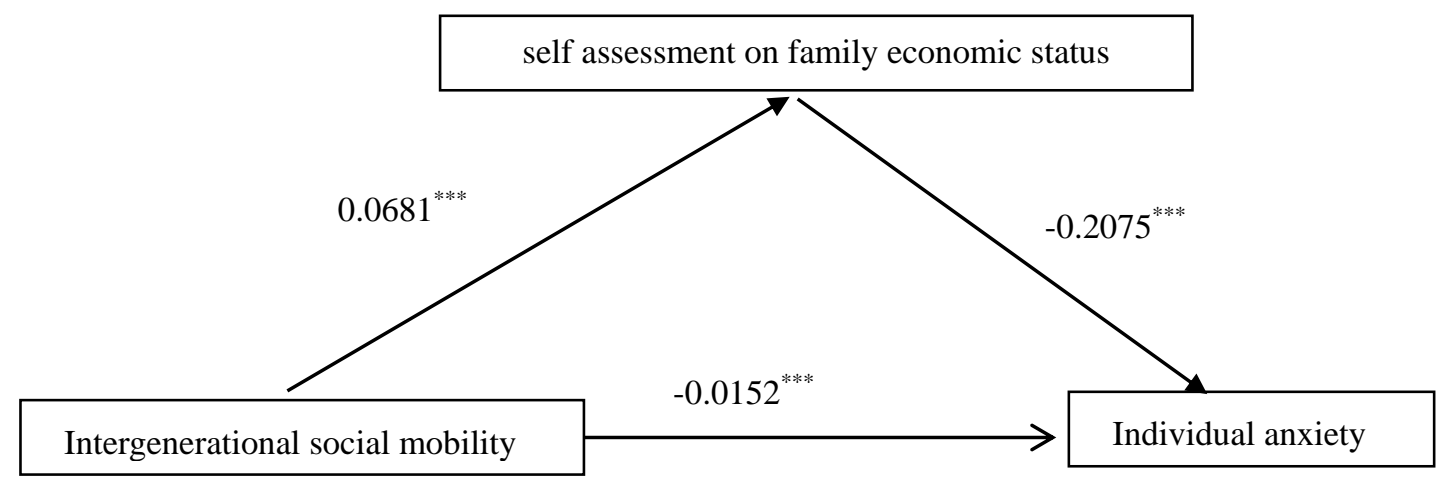

Figure 2. The mediating effects of family economic status between Intergenerational social mobility and anxiety

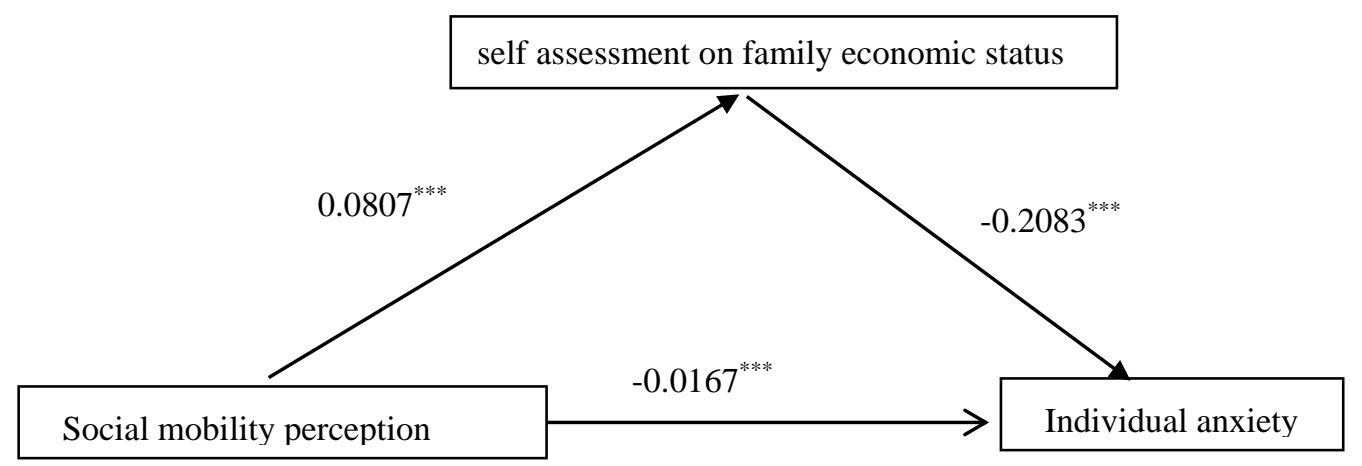

Figure 3. The mediating effects of family economic status between Social mobility perception and anxiety

\subsection{Discussion}

According to the above empirical results, not only static indicators such as the subjective class identification, but also dynamic indicators including intergenerational social mobility and social mobility perception can alleviate individual anxiety. In addition, self assessment on family economic status play a significant mediating role. The underlying mechanism maybe that the leaping or rising of class brings the improvement of family income, so as to reduce anxiety.

In view of the research findings, this paper believes that we should further strengthen the social function of social security, medical care, education and employment policies to ensure the basic living security of residents, especially the underprivileged residents, and gradually relieve the sources of pressure. Another is to further deepen social reform, break through the barriers of high-interest groups, gradually establish an benefit balance mechanism among different classes as a "safety valve" of class conflicts, and provide stable psychological expectations for the upward mobility. The last but the most important policy is to develop economy and promote social structural mobility.

\section{Conclusion}

Using 17192 samples from the Chinese General Social Survey (CGSS) in 2010, 2012, 2013 and 2015, this paper studies 
the impact of subjective class identification and social mobility (including intra and inter-generational mobility) on individual anxiety, and the mediating effect of family economic status.

Through the ordered probit regression model, it is found that the increase of positive mobility distance can alleviate individual anxiety to a certain extent, whether it is intra or inter-generational mobility. At the same time, the higher the score of subjective class identification, the lower the degree of individual anxiety, and there is also a significant negative relationship between them.

Positive social mobility can improve the economic income of individuals or families so as to reduce their anxiety. Further research is done with self assessment on family economic status as mediating variables. The results show that family economic status has a significant mediating effect on the relationship among subjective class identification, intra and inter-generational mobility and individual anxiety.

This study is not without limitations. Firstly, individual anxiety is a complex psychological concept, which needs to be measured with more scientific and comprehensive indicators; Secondly, we need to further test the robustness of the relationship between social mobility and individual anxiety. Future research needs to further explore the underlying mechanism between social mobility and individual anxiety.

\section{Funding}

This research was funded by The National Social Science Fund of China "Research on the formation mechanism and promotion strategy of relative poor population's sense of gain from the perspective of social mobility", grant number 20BSH128.

\section{References}

Chan, W. T. (2017). Social mobility and the well-being of individuals. The British Journal of Sociology, 69(1), 183-206, https://doi.org/10.1111/1468-4446.12285

Daenekindt, S. (2017). The Experience of Social Mobility: Social Isolation, Utilitarian Individualism, and Social Disorientation. Social Indicators Research, 133(1), 15-30. https://doi.org/10.1007/s11205-016-1369-3

Department of Migrant Population Services Management in China. (2011). Report on the China's Migrant Population Development. Beijing: China Population Publishing Press.

Gay, P. (1984). The Cultivation of Hatred: The Bourgeois Experience. Oxford: Oxford University Press.

Gu, H. (2015). Study of Class Solidification from the Perspective of Social Mobility: an analysis of the changes of social class mobility in China since the reform and opening up. Social Sciences in Guangdong, 5, 202-213.

Hua, H. Q., \& Weng D. J. (2013). Social Status, Life Situation and Anxiety. Society, 33(01), 136-160.

Hunt, A. (1999). Anxiety and Social Explanation: Some Anxieties about Anxiety. Journal of Social History, 32(3), 509-528. https://doi.org/10.1353/jsh/32.3.509

Kohn, M. L. et al. (1997). Social Structure and Personality Under Conditions of Radical Social Change: A Comparative Analysis of Poland and Ukraine. American Sociological Review, 62(4), 614-638. https://doi.org/10.2307/2657430

Kraus et al. (2012). Social Class, Solipsism, and Contextualism: How the Rich Are Different From the Poor. Psychological Review, 119(3), 546-572. https://doi.org/10.1037/a0028756

Lauren, B., \& Alloy. (2006). Abnormal Psychology. Shanghai: Shanghai Academy of Social Sciences Press.

Li, L. L. (2006). Reproduction and Governance: Rethinking the Mechanism of Social Mobility. Sociological Research, 2, 37-60.

Li, Q. (2011). Ten lectures on Social Stratification. Beijing: Social Sciences Academic Press.

Lu, X. Y. (2004). Social Mobility in Contemporary China. Beijing: Social Sciences Academic Press.

Merkl, P., \& Turner, F. C. (1993). Social Mobility and Political Attitudes: Comparative Perspectives. American Political Science Review, 87(3), 806-807. https://doi.org/10.2307/2938795

Qiu, M. (2003). Social Anxiety - A Micro-level Social Problem. Society, 3, 8-9.

Shi, C., \& Zhao Z. H. (2011, October 21). China has entered a period of "national anxiety", and social injustice aggravates the anxiety. Retrieved from http://cn.chinagate.cn/society/2011-10/21/content_23688065_2.htm

Sun, L. P. (2003). Fracture: Chinese Society since 1990s. Beijing: Social Sciences Academic Press.

Sun, Y. T. (2016). Study on the Status Anxiety of Urban Residents. Journal of Fujian provincial Party School of CPC, 5, 66-72. 
Tashiro, N. (2008). Anxiety and Psychological Conflict. Beijing: People's Medical Publishing Press.

Wei, J. F. (2017). Class Differentiation, Intergenerational Division of Labor and the Willingness of the New Generation of Migrant Workers to Participate in Entrepreneurship. Macro Economics, 6, 132-146

Wu, Z. M. (1993). Attention to the Study of Social Anxiety. Fujian Forum, 2, 60-61

Zhang, Y. (2011). Research on the Changing Trend of China's Social Class Structure - Based on the Analysis of the CGSS Survey Data. Studies on the Socialism with Chinese Characteristics, 3, 65-74

Zhaopin. (2018, May 19 ). Zhaopin released "2018 white-collar life survey report". Retrieved from https://www.sohu.com/a/232169728_162522

\section{Copyrights}

Copyright for this article is retained by the author(s), with first publication rights granted to the journal.

This is an open-access article distributed under the terms and conditions of the Creative Commons Attribution license which permits unrestricted use, distribution, and reproduction in any medium, provided the original work is properly cited. 